\title{
CORRIGENDUM
}

\section{High-velocity collisions from the lunar cataclysm recorded in asteroidal meteorites}

S. Marchi, W. F. Bottke, B. A. Cohen, K. Wünnemann, D. A. Kring, H. Y. McSween, M. C. De Sanctis, D. P. O'Brien,

P. Schenk, C. A. Raymond and C. T. Russell

Nature Geoscience 6, 303-307 (2013); published online 24 March 2013; corrected after print 24 March 2013.

In the print version of this Article, in the 7th author affiliation the US state is incorrect; it should read 'Arizona'. The 'accepted' date of the Article is also incorrect; it should read 8 February 2013. These errors are correct in the HTML and PDF versions. 